\title{
Expanded perlite/cork fillers applied to aerospace insulation materials
}

\author{
JULIANO R.A. PINTO ${ }^{1,2}$, NATALIA B. SANCHES ${ }^{3}$, MILTON F. DINIZ ${ }^{4}$, RÉGIS S. \\ SANTOS $^{2}$, JOSÉ I.S. DE OLIVEIRA ${ }^{1,2}$ and RITA DE CÁSSIA L. DUTRA ${ }^{1}$ \\ ${ }^{1}$ Departamento de Química, Instituto Tecnológico de Aeronáutica/ITA, Avenida Marechal do Ar \\ Eduardo Gomes, 50, Vila das Acácias, 12228-900 São José dos Campos, SP, Brazil \\ ${ }^{2}$ Divisão de Produção de Motores/APM, Estrada Municipal Lúcia Marcondes e Machado \\ Penedo, s/n, Km 4,5, Varadouro, 12315-020 Jacareí, SP, Brazil \\ ${ }^{3}$ Centro Universitário Sant'Anna/UNISANT'ANNA, Rua Voluntários da Pátria, 257, 02011-000 Santana, SP, Brazil \\ ${ }^{4}$ Divisão de Química do Instituto de Aeronáutica e Espaço/IAE, Avenida Marechal do Ar \\ Eduardo Gomes, 50, Vila das Acácias, 12228-904 São José dos Campos, SP, Brazil
}

Manuscript received on November 26, 2017; accepted for publication on April 4, 2018

\begin{abstract}
Insulations for rocket motors such as Flexible Thermal Protections (FTPs) and Rigid Thermal Protection (RTPs) act as thermal barriers against the hyperthermal environment from the solid propellant combustion. FTPs present dual function: to extend RTPs performance, and to attenuate the propellant contraction. FTPs used in the Brazilian Space Program have asbestos in their composition since the 70's; however, they are hazardous for human health. In this context, a mixture of Expanded Perlite (PExp) and Cork Powder (CP) was investigated as a replacement for asbestos. Results showed reduction about $21 \%$ in density and an increase of $13 \%$ in the ablative properties. The low mechanical properties not interfere in this type of FTP due to your function of attenuate the propellant contraction.
\end{abstract}

Key words: asbestos replacement, cork, HTPB, insulation, perlite.

\section{INTRODUCTION}

Thermal insulation of rocket motors main function is to act as a thermal barrier between the gases and the heat generated by the combustion of the solid propellant. It consists of several components to achieve this goal (Koo et al. 2010, Douglass 1976, Zhang et al. 2016).

The inside of the rocket motor, or booster, developed by a Brazilian Research Center ("Instituto de Aeronáutica e Espaço" - IAE) is

Correspondence to: Rita de Cássia Lazzarini Dutra

E-mail: ritalazzarini@yahoo.com.br composed of an adhesive and thermal coating, called liner. The liner acts as an adhesive interface between the propellant and the Flexible Thermal Protections (FTPs) and Rigid Thermal Protection (RTPs) located in the front and rear domes. FTPs and RTPs are designed to protect the combustion chamber from high heat and mass flows (Palmerio 2017).

Composite materials have an extensive application in the aerospace industry as FTPs and RTPs because they combine good mechanical and thermal properties, besides being capable of forming a residual char layer during the pyrolysis 
process. This char layer is mostly the responsible for the material ablative resistance (Silva et al. 2011, Yum et al. 2015, Natali et al. 2016a, Zhang et al. 2016).

Ablation is the process that delays the heat and mass transfer during the solid propellant combustion because of the slow and continuous consumption of the material that constitutes the thermal protection (Yum et al. 2015). This process is able to dissipate the high heat flux by the chemical and physical decomposition of the thermal insulation material, i.e., it transforms thermal energy in mass loss (Helber et al. 2012, Ahmad et al. 2014).

In addition to forming the char layer during the polymeric matrix pyrolysis, solid fillers added to the thermal insulation also act as a barrier to thermal insulation wear, mostly reducing the mechanical erosion process originated from the mass flow of the combustion gases (Yang et al. 2012, Borner et al. 2015).

Numerous materials have been tested and used in thermal insulation systems, such as glass, carbon and aramid fibers, silicon and iron oxides, carbides, asbestos, all with the purpose of acting as support for the char layer (Natali et al. 2016a, Deuri et al. 1988, Zhang et al. 2016).

In this context, cork is a biological material origin from the bark of the Quercus Suber L. tree. Used in insulation, its main function is to act as a protective layer. Because of its composition and chemical structure, cork is a versatile material in a wide range of applications, from bottle corks to thermal and acoustic insulation components (Pereira 2007, Sen et al. 2014).

From the chemical point of view, cork contains two categories of materials: the structural ones that confer stability and resistance to the cork cells, and the non-structural ones that confer other properties such as impermeability (Pereira 1992). Among the structural components, suberin and lignin are the most important on account of their stability during the pyrolysis and thermal degradation process of the propellant combustion. They also are mostly responsible for the formation of the char layer (Silva et al. 2005, Mestre et al. 2006, Cordeiro et al. 1998, Sen et al. 2014).

For aerospace applications, cork stands as an interesting material, considering not only its characteristics of impermeability, low specific mass, thermal and acoustic insulation, but also its excellent ablative resistance, even when mixed with other components. However, it can reduce the mechanical properties of composites, which can be prevent using specific coupling agents. (Pereira 2007, Silva et al. 2011, Petit et al. 2007).

Perlite is another material with interesting properties. It is an amorphous mineral of volcanic origin rich in aluminosilicates and silicon oxide, and containing 2 to $5 \%$ of water molecules trapped in its structure. Its name derives from the perlstein term and means rock with concentric cracks, similar to a broken pearl (Dogan and Alkan 2004, Arifuzzaman and Kim 2015a, Oktay et al. 2015, Celik et al. 2016, Maaloufa et al. 2015). When heated at temperatures above $870{ }^{\circ} \mathrm{C}$, its structure becomes softer. The trapped water vaporizes expanding the beads of perlite about 10 to 30 times, thus, making it porous, hence forth known as expanded perlite (Gürsoy and Karaman 2016, Celik et al. 2016, Pilatos et al. 2016).

Expanded perlite is one of the few materials that associate the properties of lightness, sterility, thermal and acoustic insulation, resistance to fire, and the fact that it is incombustible. Thus, it is very important in fire resistant applications (Gürsoy and Karaman 2016, Shoukry et al. 2016).

Kallergis et al. (2013) and Sahraeian et al. (2013) verified that perlite tends to form a char layer on the pyrolyzed surface of a polyethylene composite, precisely because it exhibits good thermal resistance when subjected to the combustion and pyrolysis processes.

Although the results of Kallergis et al. (2013) and Sahraeian et al. (2013) concluded that perlite 
produces a char layer during pyrolysis, they did not evaluate the use of perlite in thermal protection systems (TPS) applied to combustion chambers of rocket motors. Recently Natali et al. (2016a) published a review on the diverse types of ablative thermal protection systems for rocket motors, but the use of expanded perlite alone or mixed with any other material was not discussed.

In this scenario, the present study proposes the use of a cork powder and expanded perlite mixture for the development of flexible thermal protections for use in the interior of combustion chambers in solid propulsion rocket engines. The mixture provides dual purpose: tension relief between the solid propellant and the front and rear domes, and life extension of the rigid protection.

Furthermore, the formulation used is asbestosfree, which will allow the continuity of the Brazilian Space Program, given that asbestos has already been completely banned in countries such as Norway, Germany, Sweden and Australia and that Brazil is in process of prohibition the exploitation and use of this material throughout the national territory.

\section{MATERIALS AND METHODS}

\section{MATERIALS}

Hydroxyl-terminated polybutadiene (HTPB) (hydroxyl value $\left(\mathrm{I}_{\mathrm{OH}}\right) 0.82 \mathrm{mmol} \mathrm{g}^{-1}$ ), from Liquiflex Brazil, Expanded Perlite (PExp) SF22, from Schumacher Insumos Brazil, Cork powder (CP), from Cork Trianon Brazil, and Toluene-2,6Diisocyanate - $97 \%$ (TDI) Voranate T80, from Isopol, Brazil were the main materials used.

\section{SAMPLE COMPOSITIONS}

Samples of PExp/CP blends were prepared as shown in Table I. PExp5 is a formulation with 5 parts of expanded perlite; CP5 is a formulation with 5 parts of cork powder; PExp5/CP3 is a mix of 5 parts of expanded perlite and 3 parts of cork powder and the formulation PExp5/CP5 have in your composition 5 parts of expanded perlite and cork powder.

Quantities of expanded perlite and cork powder were determined based on the viscosity not superior to $45000 \mathrm{cP}$ at $30{ }^{\circ} \mathrm{C}$ for the casting of a full-size thermal protection.

The FTP reference is a material that has in your composition asbestos fiber and other fillers that give good mechanical and ablative properties, however, the asbestos in a carcinogenic material and these mix of fillers results in a FTP extremely dense and heavy, properties undesirable for aerospace applications.

Preparation of the Formulations: Initially, HTPB resin was heated and maintained around $60{ }^{\circ} \mathrm{C}$, while fillers at $120^{\circ} \mathrm{C}$ for 2 hours. HTPB resin, ferric acetyl acetonate catalyst $\mathrm{Fe}\left(\mathrm{C}_{5} \mathrm{H}_{7} \mathrm{O}_{2}\right)_{3}$ $97 \%$ (Aldrich), and the fillers were weighed and homogenized according to the formulations. They were then degassed for the addition and mixing of the TDI curing agent.

Specimens of each formulation were prepared for the mechanical tensile and elongation tests, as well as for the oxy acetylene torch ablation test. The specimens were cured at $60{ }^{\circ} \mathrm{C}$ for 24 hours, and then, were subjected to post cure at ambient conditions for another 7 days, so that the mechanical properties were fully achieved (Crespim et al. 2007).

TABLE I

Formulations of PExp/CP samples.

\begin{tabular}{ccccc}
\hline Components & PExp5 & CP5 & $\begin{array}{c}\text { PExp5/ } \\
\text { CP3 }\end{array}$ & $\begin{array}{c}\text { PExp5/ } \\
\text { CP5 }\end{array}$ \\
\hline $\begin{array}{c}\text { HTPB } \\
\begin{array}{c}\text { Expanded } \\
\text { Perlite }\end{array}\end{array}$ & 100 & 100 & 100 & 100 \\
$\begin{array}{c}\text { Cork Powder } \\
\text { Fe }\left(\mathrm{C}_{5} \mathrm{H}_{7} \mathrm{O}_{2}\right)_{3}\end{array}$ & 0 & 0 & 5 & 5 \\
TDI & 7.012 & 0.012 & 0.012 & 0.012 \\
\hline
\end{tabular}




\section{CHARACTERIZATION METHODOLOGIES}

Morphology of expanded perlite and cork particles

The shape of the expanded perlite and cork powder particles was evaluated by an optical stereomicroscope Carl-Zeiss, model Discovery V12.

Characterization of fillers by granulometric analysis

The granulometric analysis of expanded perlite and cork powder particles were performed in a MASTERSIZER 2000 equipment, from MALVERN Instruments. The fillers were evaluated using water as a dispersant, in liquid medium, and ultrasound to disperse the particles. Testing environmental conditions were temperature between 19.2 and $20.1{ }^{\circ} \mathrm{C}$, and relative humidity between 36.5 and $37.4 \%$.

\section{Mechanical and specific mass tests}

The tensile strength and elongation tests of ten samples were carried out in a ZWICK 1474 traction equipment, and were performed in accordance to the ASTM D412 / NBR 7462 - Type "F" standard. The specimen's hardness was determined in an INSTRON S1 hardness tester, in accordance to the ASTM D2240-05 standard. The specimen's specific mass was determined by the hydrostatic method.

\section{Dispersion of perlite particle in matrix}

Sample was analyzed by SEM, on a Zeiss LEO 435 VPi field-emission scanning microscope.

Oxy acetylene torch (OAT) ablation tests

Ablation tests were conducted in equipment developed on the "Divisão de Química" of the IAE, in which an oxy acetylene torch is used to provide a high flow of heat in order to simulate the conditions created by the combustion of the propellant inside the rocket motor chamber. The heat flux was in the order of $(800 \pm 20) \mathrm{W} \mathrm{cm}^{-2}$. Testing methodologies were in accordance to the ASTM-E-285-08 standard.

Due to the data are not disclosed, because of the confidentiality related to the used thermal protection properties, to confirm the ablative properties improvement of the PExp/CP blends, normalization methods (Natali et al. 2016a) of the results were used in relation to the flexible thermal protection currently employed in the rocket motors projects of IAE.

\section{FT-IR characterization}

Fourier transform infrared (FT-IR) spectra were obtained in a Spectrum One FT-IR spectrometer, spectral range of 4000 to $550 \mathrm{~cm}^{-1}$ (medium infrared - MIR), resolution of $4 \mathrm{~cm}^{-1}$, by reflection mode. Reflection mode was obtained by using the universal attenuated total reflection (UATR) accessory. The samples surface was analyzed prior to and after the ablation test.

\section{RESULTS AND DISCUSSION}

\section{PARTICLES MORPHOLOGY}

Figure 1 shows the optical stereomicroghaphs of neat expanded perlite and cork powder. It shows that both the PExp and the CP particles present porous structures, as expected, which give the formulations a low density, low thermal and low acoustic conductivity, among other properties.

\section{GRANULOMETRIC ANALYSIS}

Granulometric analysis of the PExp powder and CP powder resulted in the granulometric distribution showed in Table II.

$\mathrm{d}(0.1)=10 \%$ of the sample volume has particles below the indicated values. 


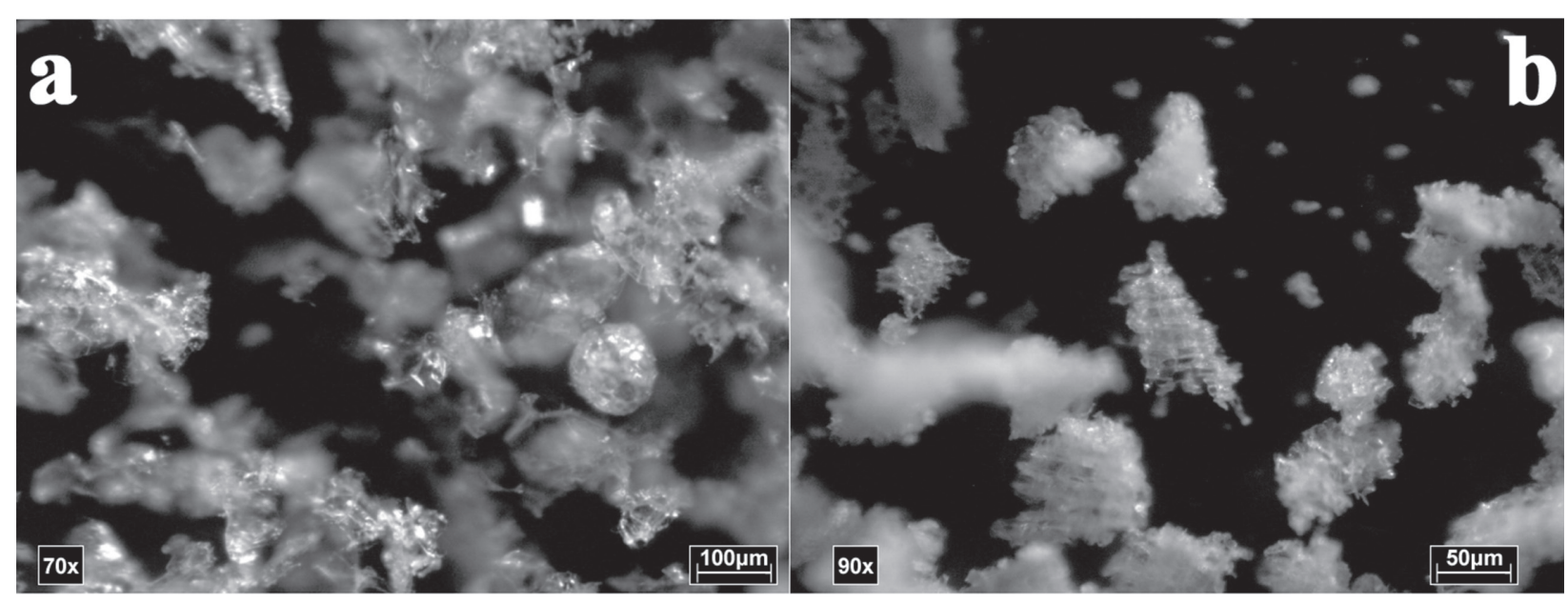

Figure 1 - Stereomicrographs of PExp (a) and CP (b). Magnification of 70 and 90x, respectively.

$\mathrm{d}(0.5)=50 \%$ of the sample volume has particles below the indicated values.

$\mathrm{d}(0.9)=90 \%$ of the sample volume has particles below the indicated values.

$\mathrm{D}[4.3]=$ medium diameter of the particles.

The values that best represent results of the PExp and CP granulometry are the medians $\mathrm{d}(0.5)$. Thus, the used expanded perlite and the cork powder have an average particle size $\mathrm{d}(0.5)$ equal to $(53 \pm 1) \mu \mathrm{m}$ and $(55 \pm 1) \mu \mathrm{m}$ respectively.

\section{MECHANICAL PROPERTIES AND DENSITY}

Table III shows mechanical properties and density results for the studied formulations, were $\sigma$ is the tensile strength, $\varepsilon$ the strain, E the Young's modulus, $H$ the hardness and $\rho$ the density.

A comparison between FTP and Pexp5 results shows a reduction in the mechanical properties of the Pexp5 formulation. This outcome can be mainly attributed to two factors: first, to the hydrophobicity of the resin and the hydrophilic characteristic of the expanded perlite particles; and second, to the low mechanical properties of the perlite particles (Arifuzzaman and Kim 2015b, Amrollahi and Sadeghi 2016, Gürsoy and Karaman 2016). The first factor causes low interfacial adhesion between the filler and the matrix, as can be seen in Figure 2, were the black space around the fillers is related to poor
TABLE II

Granulometric distribution of PExp and CP.

\begin{tabular}{ccccc}
\hline \multirow{2}{*}{ Sample } & \multicolumn{3}{c}{ Distribution $(\boldsymbol{\mu m})$} & $\begin{array}{c}\text { Medium } \\
\text { Diameter }(\boldsymbol{\mu m})\end{array}$ \\
\cline { 2 - 5 } & $\mathbf{d}(\mathbf{0 . 1})$ & $\mathbf{d}(\mathbf{0 . 5})$ & $\mathbf{d}(\mathbf{0 . 9})$ & $\mathbf{D}[4.3]$ \\
\hline $\begin{array}{c}\text { Expanded } \\
\text { Perlite } \\
\begin{array}{c}\text { Cork } \\
\text { Powder }\end{array}\end{array}$ & $15 \pm 1$ & $53 \pm 1$ & $158 \pm 1$ & $76 \pm 1$ \\
\hline
\end{tabular}

TABLE III

Results of mechanical properties and density.

\begin{tabular}{cccccc}
\hline Sample & $\begin{array}{c}\boldsymbol{\sigma} \\
(\mathbf{M P a})\end{array}$ & $\begin{array}{c}\boldsymbol{\varepsilon} \\
(\mathbf{\%})\end{array}$ & $\begin{array}{c}\mathbf{E} \\
(\mathbf{M P a})\end{array}$ & $\begin{array}{c}\mathbf{H} \\
(\mathbf{S h . A})\end{array}$ & $\begin{array}{c}\boldsymbol{\rho} \\
(\mathbf{g ~ c m}\end{array}$ \\
\hline FTP & $1.98 \pm$ & $157 \pm$ & $3.57 \pm$ & $58 \pm 1$ & $1.151 \pm$ \\
& 0.17 & 11 & 0.44 & & 0.001 \\
PExp5 & $1.50 \pm$ & $132 \pm$ & $3.09 \pm$ & $52 \pm 1$ & $0.951 \pm$ \\
& 0.04 & 11 & 0.07 & & 0.001 \\
CP5 & $1.84 \pm$ & 179 & $2.64 \pm$ & $47 \pm 1$ & $0.926 \pm$ \\
& 0.08 & \pm 9 & 0.16 & & 0.002 \\
PExp5/ & $1.49 \pm$ & 147 & $3.16 \pm$ & $50 \pm 1$ & $0.953 \pm$ \\
CP3 & 0.08 & \pm 4 & 0.19 & & 0.001 \\
PExp5/ & $1.55 \pm$ & 190 & $2.83 \pm$ & $50 \pm 1$ & $0.949 \pm$ \\
CP5 & 0.02 & \pm 4 & 0.09 & & 0.002 \\
\hline
\end{tabular}

interaction of perlite particles and HTPB matrix. The second factor is originated after the process of thermal expansion and produces a structure with relatively thin walls, which concentrates tension during the tensile test and becomes the main point of rupture in the matrix. Both factors lead to a decrease in elongation and tensile stress. 
On the other hand, the CP5 result showed improvement in elongation, but a reduction in the tensile stress, when comparing to the FTP sample. The difference in properties can be attributed to the hydrophobic characteristic of cork, causing poor interfacial interaction between the filler and the matrix. On the other side, cork's good elastic properties contribute to the improvement in elongation (Motte et al. 2017). According to Barbosa et al. (2017), composites made with smaller sizes of cork particles present less fragility when compared to the ones made with larger particles. This fact causes the CP5 formulation, which has only $5 \mathrm{phr}$ of small particles of cork, to present properties that approximate the FTP, which contains about $47 \mathrm{phr}$ of other types of fillers.

Results of PExp5/CP3 and PExp5/CP5 formulations were as expected, as the expanded perlite particles act as the weak point for fracture within the matrix, as explained by Amrollahi and Sadeghi (2016) and Gürsoy and Karaman (2016), even if there is a good interaction between the matrix and the cork powder particles. It is also emphasized that the interaction between matrix and cork powder within the PExp5/CP5 formulation leads to an improvement in elongation, even though maintaining tensile stress at similar levels.

On the other hand, as pointed out by Gürsoy and Karaman (2016) and Motte et al. (2017), both expanded perlite and cork powder have porous

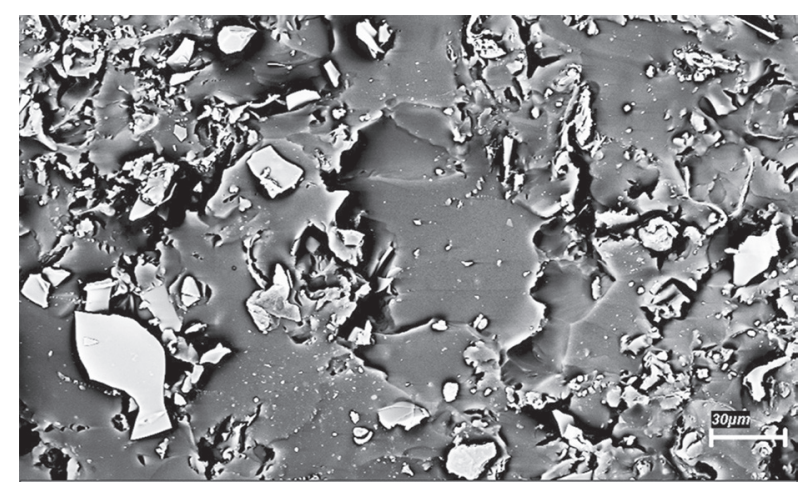

Figure 2 - SEM micrograph of dispersion of perlite particles in HTPB matrix. structures that make them light and, when added in the HTPB matrix as fillers, give the final material lower density, which evidently is of great interest for the aerospace industry.

\section{ABLATIVE PROPERTIES}

Table IV and Figure 3 present the burning time and erosion rate results. According to the ASTM-E-285-08 standard, the Burn Time $\left(\mathrm{T}_{\mathrm{b}}\right)$ test refers to the time required for the heat flow to pass through the sample. In addition, the Erosion Rate, E, is the ratio between sample thickness and burn time. Results were normalized by the ratio between the firing time and the ablation velocity of the samples and the FTP results.

Results on Figure 4 show that the burn time and erosion rate of the formulations containing only perlite (PExp5) and cork (CP5) do not satisfactorily reach the time and erosion reported by the reference FTP. However, even in smaller amounts than those present in the FTP formulation, the presence of perlite and cork in the resin is sufficient to form char layer that act as a protective barrier against the heat and mass flow of the oxy acetylene torch. As stated by Sen et al. (2014), cork presents a good ability to form the char layer, as well as expanded perlite (Kallergis et al. 2013).

On the other hand, the mixture of fillers in the formulations PExp5/CP3 and PExp5/CP5 offered better ablative properties than the FTP, corroborating once again with Sen et al. (2014) and Kallergis et al. (2013). In this case, the synergism between perlite and cork caused the ablative

TABLE IV

Normalized results for Burn Time $\left(T_{b}\right)$, and Erosion Rate (E).

\begin{tabular}{|c|c|c|c|c|c|}
\hline m & $\mathbf{P}$ & $\mathbf{F} \mathbf{x}$ & P5 & $\begin{array}{c}\text { PExp5/ } \\
\text { CP3 }\end{array}$ & $\begin{array}{c}\text { PExp5/ } \\
\text { CP5 }\end{array}$ \\
\hline & & 0.0 & 0.0 & $\begin{array}{c}1.06 \pm \\
0.03\end{array}$ & $\begin{array}{c}1.13 \pm \\
0.07\end{array}$ \\
\hline E (n & & $\begin{array}{c}1.07 \pm \\
0.10\end{array}$ & $\begin{array}{c}1.05 \pm \\
0.09\end{array}$ & $\begin{array}{c}0.94 \pm \\
0.04\end{array}$ & $\begin{array}{c}0.87 \pm \\
0.04\end{array}$ \\
\hline
\end{tabular}


resistance of these formulations to be superior than the FTP's. The amount of cork present helps increasing the burning time and decreasing the rate of ablation due to the amount of carbonaceous residue (char) formed.

\section{FT-IR/UATR ANALYSIS OF SAMPLE SURFACE}

It is important to investigate the surface of the materials to assess their ablative properties, which was done by FT-IR/UATR analysis. According to Pedreira et al. (2016), FT-IR/UATR is a technique able to evaluate a thin surface layer, being capable of assess the differences occurring on the sample before and after the ablation tests. Figures 4 and 5 show the FT-IR/UATR spectra prior and subsequent the ablation test.

As can be seen in Figure 4a, b, spectra are similar indicating the presence of the cured HTPB layer, i.e., the expanded perlite is not exposed on the surface of the sample before ablation. After the ablation process, the presence of the perlite particles on the surface where the pyrolysis process occurred (Figure 4c) is noticeable on the spectra changes. The widening of the band around 1000$1200 \mathrm{~cm}^{-1}$ is attributed to the vibrational stretching of the Si-O bonds of the Si-O-Si groups, and the appearance of a band by $780 \mathrm{~cm}^{-1}$ is attributed to the vibrational stretching of the $\mathrm{Si}-\mathrm{O}$ bonds of the Si-O-Al groups (Smith 1979, Edebali 2015). The similarity between the after ablation spectrum (Figure 4c) and the powdered perlite spectrum (Figure 4d) is evident.

The exposure of the perlite particles during the pyrolysis process is responsible for the improvement in the ablative properties. As observed by Sahraeian et al. (2013) and Kallergis et al. (2013), the perlite particles are chemically inert, resistant to combustion and tend to form an inorganic layer upon exposure to the matrix pyrolysis, which decreases the rate of degradation of the matrix.

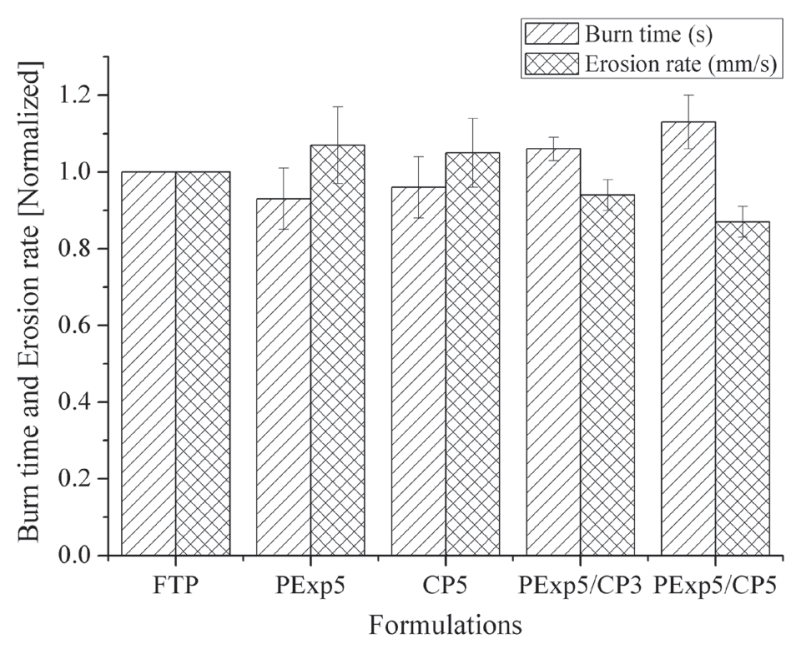

Figure 3 - Burn time and erosion rate for the formulations studied.

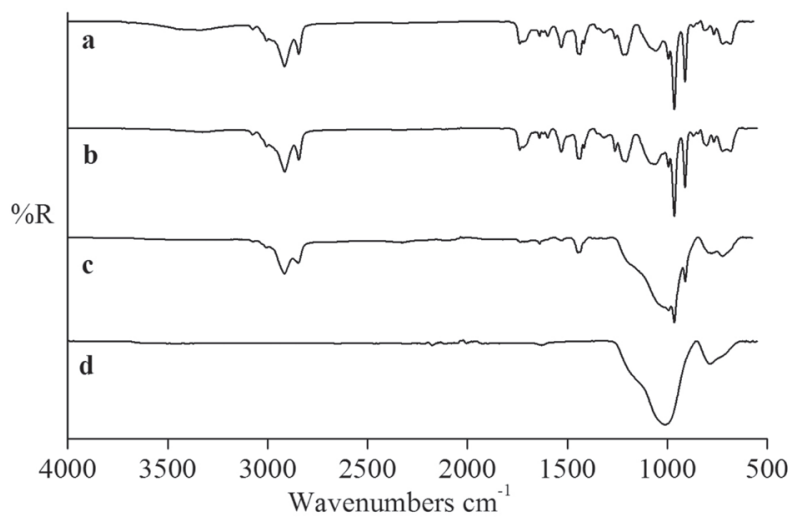

Figure 4 - FT-IR/UATR spectra before and after the ablation test: a) cured HTPB; b) PExp5 before ablation; c) PExp5 after ablation; and d) PExp powder.

Figure 5 shows the FT-IR/UATR results on the samples surfaces submitted to the OAT ablation test for formulations containing only cork powder and mixed with expanded perlite.

The main absorptions observed in Figure $5 \mathrm{a}$ are $3360 \mathrm{~cm}^{-1}$ (attributed to the stretching of the $\mathrm{OH}$ groups of suberin), 2920 and $2850 \mathrm{~cm}^{-1}$ (due to stretching of the $\mathrm{CH}_{2}$ and $\mathrm{CH}_{3}$ bonds of the suberin hydrocarbon chains), $1740 \mathrm{~cm}^{-1}$ (of the stretching of the $\mathrm{C}=\mathrm{O}$ bonds of aliphatic acids and their esters in suberin), and $1160 \mathrm{~cm}^{-1}$ (attributed to stretching of the COC groups of ester groups in suberin). Suberin is the structural component of corks and 


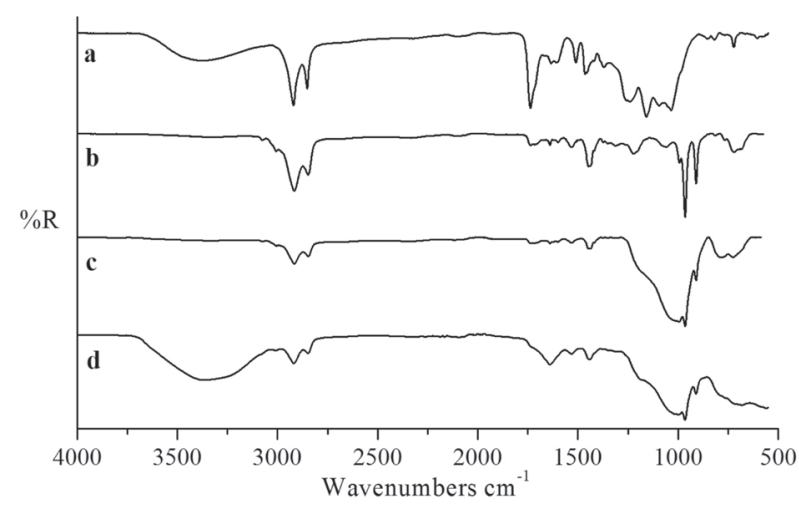

Figure 5 - FT-IR/UATR spectra of: a) Cork powder; b) CP5 after the ablation; c) PExp5/CP3 after the ablation; d) PExp5/ CP5 after the ablation.

mostly responsible for the formation of the char layer (Natali et al. 2016b, Sen et al. 2014).

Figure $5 \mathrm{~b}$ shows the surface analysis of the CP5 formulation after the ablation test in OAT. Bands in 2920 and $2850 \mathrm{~cm}^{-1}$ from the suberin hydrocarbon chains are observed with greater intensity, so it is possible to confirm the powdered cork particles influence on the formation of the char layer and its retarding effect on the ablation rate (Natali et al. 2016b, Sen et al. 2014).

The increase in the firing time of the PExp5/ CP3 and PExp5/CP5 formulation is explained in Figure $5 \mathrm{c}$, $\mathrm{d}$. It is possible to observe the absorptions relative to the presence of both cork powder and expanded perlite. The band around 1000-1200 $\mathrm{cm}^{-1}$ is attributed to the vibrational stretching of the Si-O bonds of the Si-O-Si groups present in perlite, and the appearance of absorptions around $3362 \mathrm{~cm}^{-1}$ is attributed to the $\mathrm{OH}$ groups of suberin in the PExp5/CP5 formulation. This explains why this formulation resists a longer time in the OAT ablation process.

The cork particles are good carbonaceous residue forming, and the perlite particles form a layer of inorganic material that helps to reduce the diffusion of the oxidant chemical species to the lower layers. The combine effect of these fillers makes the final formulation more resistant to ablation. It can noticed that the increase in the content of cork in the formulation improves the ablative properties due to the higher amount of carbonaceous residue (char) formed in the formulations containing 3 and $5 \mathrm{phr}$ of powdered cork (Petit et al. 2007, Kallergis et al. 2013, Sen et al. 2014).

\section{CONCLUSIONS}

The tests results indicate that the mixture between the expanded perlite and the cork powder in the HTPB matrix produces a material with better ablative resistance when compared to the FTP currently used. The reason for this improvement is observed in the FT-IR/UATR spectra of the surfaces after pyrolysis, which shows the formation of an inorganic perlite layer that acts as a second protective layer after removal of the cork particles.

Regarding to the low mechanical properties results, the fillers do not necessarily have the characteristic of acting as reinforcement material. Nevertheless, they provide a lower density that is the great interest characteristic.

Thus, taking into account that the FTP design allows the obtained mechanical properties results, the formulation PExp5/CP5 are the most suitable to replace the existing FTP formulation by associating good ablative strength with a low density.

\section{ACKNOWLEDGMENTS}

This study was supported partially by the National Senior Visiting Professor Program (PVNS) from the Coordenação de Aperfeiçoamento de Pessoal de Nível Superior (CAPES).

\section{REFERENCES}

AHMAD MS, FAROQ U AND SUBHANI T. 2014. Postablation micro-structural analysis of nanoparticle reinforced carbon fiber epoxy matrix composite. J Space Technol 4: 101-107.

AMROLLAHI M AND SADEGHI GMM. 2016. Assessment of adhesion and surface properties of polyurethane coatings 
based on non-polar and hydrophobic soft segment. Prog Org Coat 93: 23-33.

ARIFUZZAMAN MD AND KIM HS. 2015a. Novel mechanical behavior of perlite/sodium silicate composites. Constr Build Mater 93: 230-240.

ARIFUZZAMAN MD AND KIM HS. 2015b. A model of foam density prediction for expanded perlite composites. MATEC Web Conf 26: 1-6.

BARBOSA AQ, DA SILVA LFM, ABENOJAR J, FIGUEIREDO M AND ÖCHSNER A. 2017. Toughness of a brittle epoxy resin reinforced with micro cork particles: Effect of size, amount and surface treatment. Compos Part B 114: 299-310.

BORNER A, PANERAI F AND MANSOUR NN. 2015. DSC Study of Carbon Fiber Oxidation in Ablative Thermal Protection Systems. Thermophysics Conference. $45^{\text {th }}$ AIAA Aviation. Dallas, Texas, 19 p.

CELIK S, FAMILY R AND MENGUC MP. 2016. Analysis of perlite and pumice based building insulation materials. $\mathrm{J}$ Build Eng 6: 105-111.

CORDEIRO N, BELGACEM NM, GANDINI A AND NETO CP. 1998. Cork suberin as a new source of chemicals. 1. Isolation and chemical characterization of its composition. Int J Biol Macromol 22: 77-81.

CRESPIM H, AZEVEDO MFP, DAVID LH, CASSU SN AND LOURENÇO VL. 2007. Substituição de Amianto por Silicato de Alumínio e Grafite Expansível em Compósito de Poliuretano utilizado em Motor-foguete. Polímeros 17: 228-233.

DEURI AS, BHOWMICK AK AND GHOSH R. 1988. Thermal and ablative properties of rocket insulator compound based on EPDM. Polym Degrad Stab 21: 21-28.

DOGAN M AND ALKAN M. 2004. Some physicochemical properties of perlite as an adsorbent. Fresenius Environ Bull 13: 251-257.

DOUGLASS HW. 1976. Space vehicle design criteria. Solid rocket motor internal insulation. NASA, Cleveland, Ohio, $116 \mathrm{p}$.

EDEBALI S. 2015. Alternative Composite Nanosorbents Based on Turkish Perlite for the Removal of Cr (VI) from Aqueous Solution. J Nanomater 2015: 1-7.

GÜRSOY MAND KARAMAN M. 2016. Hydrophobic coating of expanded perlite particles by plasma polymerization. Chem Eng J 284: 343-350.

HELBER B, CHAZOT O, MAGIN T AND HUBIN A. 2012. Ablation of carbon preform in the VKI Plasmatron. Thermophysics Conference. $43^{\text {rd }}$ AIAA. New Orleans, Louisiana, $13 \mathrm{p}$.

KALLERGIS G, PISANIA M AND SIMITZIS J. 2013. Manufacture and characterization of heat resistant and insulating new composite base on novolac resin - carbon fibers - perlite. Macromol Symp 331-332(1): 137-143.
KOO JH, MILLER MJ, WEISPFENNING J AND BLACKMON C. 2010. Silicone polymer composites for thermal protection system: fiber reinforcements and microstructures. J Compos Mater 0: 1-18.

MAALOUFA Y, MOUNIR S, KHABBAZI A, KETTAR J AND KHALDOUN A. 2015. Thermal characterization of materials based on clay and granular: cork or expanded perlite. Energy Procedia 75: 1150-1161.

MESTRE A, CAMPELO MG, SILVA M AND VELHINHO R. 2006. A estrutura da suberina e as suas relações com as propriedades da cortiça. Dossier info. cortiça: sector de materiais de cortiça. Design cork for future, inovation and sustainability. Susdesign, $37 \mathrm{p}$.

MOTTE J, DELENNE J, BARRON C AND DUBREUQ E. 2017. Elastic properties of packing of granulated cork: Effect of particle size. Ind Crops Prod 99: 126-134.

NATALI M, KENNY JM AND TORRE L. 2016a. Science and technology of polymeric ablative materials for thermal protection systems and propulsion devices: A review. Prog Mater Sci 84: 192-275.

NATALI M, PURI I, RALLINI M, KENNY J AND TORRE L. 2016b. Ablation modeling of state of the art EPDM based elastomeric heat shielding materials for solid rocket motors. Comput Mater Sci 111: 460-480.

OKTAY H, YUMRUTAS R AND AKPOLAT A. 2015. Mechanical and thermophysical properties of lightweight aggregate concretes. Constr Build Mater 96: 217-225.

PALMERIO AF. 2017. Introdução à tecnologia de foguetes, $2^{\text {nd }}$ ed., São José dos Campos: SindCT, 304 p.

PEDREIRA SM, PINTO JRA, CAMPOS EA, MATTOS EC, JUNIOR MSO, OLIVEIRA JIS AND DUTRA RCL. 2016. Methodologies for Characterization of Aerospace Polymers/Energetic Materials - a Short Review. J Aerosp Technol Manag 8: 2-8.

PEREIRA H. 1992. The thermochemical degradation of cork. Wood Sci Technol 26: 259-269.

PEREIRA H. 2007. Cork: Biology, Production and uses. Centro de Estudos Florestais, Instituto Superior de Agronomia, Universidade Técnica de Lisboa, $1^{\text {st }}$ ed., Amsterdan: Elsevier, $336 \mathrm{p}$.

PETIT S, BOUVET C, BERGEROT A AND BARRAU JJ. 2007. Impact and compression after impact experimental study of a composite laminate with a cork thermal shield. Compos Sci Technol 67: 15-16.

PILATOS G, SAMOUHOS M, ANGELOPOULOS P, TAXIARCHOU M, VEZIRI C, HUTCHEON R, TSAKIRIDIS P AND KONTOS AG. 2016. Carbon nanotubes growth on expanded perlite particles via CVD method: The influence of the substrate morphology. Chem Eng J 291: 106-114.

SAHRAEIAN R, ESFANDEH M AND HASHEMI SA. 2013. Rheological, thermal and dynamic mechanical studies of 
the LDPE/Perlite nanocomposite. Polym Polym Compos 21: 243-249.

SEN A, BULKE JV, DEFOIRDT N, ACKER JV AND PEREIRA H. 2014. Thermal behaviour of cork and cork components. Thermochim Acta 582: 94-100.

SMITH AL. 1979. Applied Infrared Spectroscopy, New York: J Wiley \& Sons, New York, USA, 286 p.

SHOUKRY H, KOTKATA MF, ABO-EL-ENEIN SA, MORSY MS AND SHEBL SS. 2016. Thermo-physical properties of nanostructured lightweight fiber reinforced cementitious composites. Constr Build Mater 102: 167174.

SILVA JM, GAMBOA PV, NUNES C, PAULO L AND FRANCO N. 2011. Cork: Is It a Good Material for Aerospace Structures? Structural Dynamics and Materials
Conference, $52^{\text {nd }}$ ed., AIAA/ASME/ASCE/AHS/ASC Structures. Denver, Colorado, p. 4-7.

YANG X, WEI L, SONG W AND ZHAO-HUI C. 2012. Ablative property of $\mathrm{ZrC}-\mathrm{SiC}$ multilayer coating for $\mathrm{PIP}-\mathrm{C} / \mathrm{SiC}$ composite under oxy-acetylene torch. Ceram Int 3: 2893-2897.

YUM SH, KIM SH, LEE WI AND KIM H. 2015. Improvement of ablation resistance of phenolic composites reinforced with low concentrations of carbon nanotubes. Compos Sci Technol 121: 16-24.

ZHANG G, WANG F, HUANG Z, DAI J AND SHI M. 2016. Improved Ablation Resistance of Silicone Rubber Composites by Introducing Montmorillonite and Silicon Carbide Whisker. Materials 9(9): 1-14. 